\title{
DESAINER TOYS SEBAGAI IDENTITAS GAYA HIDUP URBAN
}

\author{
Eko Priyantoro \\ (ekoyagami@yahoo.com) \\ Program Studi Magister Desain \\ Fakultas Seni Rupa dan Desain \\ Institut Teknologi Bandung \\ Jl. Ganesha no.10, Bandung.
}

\begin{abstract}
Urban area is known by higher population density and vast human type in comparison to the areas surrounding it. Quick progression of lifestyle in urban has created new variant of culture. This condition become complex discourse of urban communities. In modern culture, all phenomena that happen in urban area become the heart of trend center. Supported by high achievement in technology, new trend which happen on urban area easily spreading to rural settlements. It cause evolution in so many aspects, including of people behaviour or cultural.

Toys is one of many aspect influenced by urban culture. "Designer Toy" is the kind of product which born in urban culture. This type of toys first appeared in late 1990s and are still in production today. There is tend of many various type of Designer Toys causing by highly market demand and toy lovers awareness. According through this research, writer has concluded that Designer Toys is the one of the most popular stuff from the urban culture. Although it just a newly genre of toys, the innovation growing too fast compare to other kind of toys.
\end{abstract}

Keywords: Designer Toys, Urban, Modern Culture, Achievement in Technology. 


\section{PENDAHULUAN}

Dalam budaya perkotaan, tentu banyak timbul pergeseran nilai budaya karena faktor ilmu, politik, teknologi dan lain sebagainya. Perubahan pada wilayah kota berkembang lebih cepat dibanding dengan di desa atau komunitas yang sederhana. Urban berasal dari kata latin Urbanus atau Urbs yang berarti kota. Urban berarti sesuatu yang bersifat kota yang secara langsung maupun tidak, terkait dengan urbanisasi (perpindahan penduduk dari desa ke kota).

Budaya urban merupakan segala tindakan, tingkah laku, sikap dan berpikir manusia urban di tengah tatanan hidup kota masyarakat modern. Nilai yang dijunjung dalam kehidupan urban memiliki ciri khas sebagai pencarian dan pemuasan hasrat diri atau sering disebut juga kaum hedonis, seperti diungkapkan oleh filsuf kontemporer Michel Onfray ${ }^{1}$. Walaupun hal ini berkesan negatif namun dilihat dari aspek lain, sifat hedonisme dapat memacu semangat kompetisi yang tinggi. Dorongan semangat untuk selalu mampu untuk memuaskan hasrat pribadi, ambisi untuk bekerja menjadi kuat.

Dari segi daerah, area urban memiliki lingkungan ramai dan padat oleh penduduk, aktivitas sosial, pemukiman, ataupun bangunan-bangunan lainnya. Ciri khas yang dimiliki oleh kawasan urban adalah bangunan megah dan bertingkat, serta padat jumlah penduduk. Kesenjangan kawasan elit dan kaum pinggir dalam daerah urban memiliki jarang yang cukup signifikan dan sering menjadi problem sosial. Para penduduk kota urban memiliki mobilitas yang tinggi, sangat berbeda dengan kondisi pedesaan atau kota pinggiran. Kehidupan urban menyuguhkan beragam aktifitas yang tidak bisa ditunda, mendesak dan padat, bisa dilihat dari banyaknya kebutuhan masyarakat urban pada alat transportasi.

Designer Toys merupakan salah satu produk yang terlahir dari budaya dan gaya kehidupan masyarakat urban. Mainan/toys pada hakikinya adalah suatu alat untuk bermain. Menurut jurnal Scandinavian of Psychologyi, toys merupakan alat/tools penting yang membantu proses belajar. Dengan menggunakan mainan, anak akan diajar untuk mengembangkan daya kognitif dan mempelajari proses sebab akibat,

\footnotetext{
1 Michel Onfray seorang filsuf kontempor dari Prancis yang menjadi pakar dalam bidang hedonisme dan anarkisme. Karyanya tertuang dalam lebih dari 50 buku.
} 
mengeksplorasi tentang hubungan timbal balik dan membantu pertumbuhan fisik. Sedangkan pada orang dewasa, toys juga berfungsi sebagai alat untuk mencapai ikatan sosial, proses belajar, pencarian identitas, latihan mental dan fisik. Fungsi utama toys adalah meningkatkan daya kreativitas manusia yang nantinya menjadi bekal untuk mengembangkan fisik dan mental dalam menciptakan berbagai penemuan. Pada saat ini fungsi toys mengalami banyak perubahan fungsi seperti halnya menjadi benda koleksi, artefak atau kemajuan teknologi. Designer Toys merupakan jenis toys yang tercipta dari kebudayaan urban, sehingga ideologi urban melekat dalam wujudnya, baik secara wacana maupun secara bentuk.

Michael Lau adalah penggerak awal ide konsep dari Designer Toys. Dia dikenal sebagai desainer dan artis ilustrasi dan banyak menciptakan berbagai macam bentuk karya terutama toys. Karya diciptakannya sangat terpengaruh dengan aliran musik hip-hop Asia dan Amerika, skateboard culture dan segala ciri khas yang terjadi disekitar kawasan urban. Berasal dari latar belakang pendidik Design First Institute di Hong Kong, pada awalnya dia banyak bekerja sebagai desainer window display dan berpameran di berbagai macam galeri kecil di Hong Kong. Karyanya yang terkenal bermula dari tokoh karakter pada majalah East Touch dan membuat komik strip Gardener pada tahun 1998. Bentuk karakter dalam komiknya dibuat menjadi vynil collectible figure. Pada tahun 1999-2003 perusahaan Sony membuat kontrak sebagai distributor ekslusif karakter Gardener untuk region Asia.

Kesuksesan Michael Lau menjadi inspirasi bagi para desainer dan pelaku industri toys. Sejak saat itu bermunculan secara sporadis jenis mainan yang berangkat dari identitas karya Michael Lau dengan berbagai macam modifikasi. Segala jenis mainan seperti ini lalu disebut sebagai Designer Toys. Suatu fenomena budaya populer yang menarik untuk dijadikan bahan studi kasus dan pelengkap bahan pustaka tentang fenomena gaya hidup dari aspek desain visual. 


\section{METODE PENELITIAN}

Metode penelitian yang akan digunakan adalah metode kualitatif dengan menggunakan teknik analisis mendalam ( in-depth analysis ) yakni analisis yang terfokus terhadap aspek ilmu desain dan antropologi khususnya pop culture dan urban behaviour. Mencari data referensi tentang perkembangan Desainer Toys dengan fakta aktual dan melakukan pendekatan induktif terhadap semua hal yang terkait untuk membatasi pokok bahasan.

Penelitian ini merujuk pada desain metode penjelasan dan perkembangan (explanatory method and trend) yang bertujuan untuk memberi gambaran tentang fenomena yang terjadi dan pertumbuhan/perubahan yang terjadi pada kurun waktu tertentu. Setelah menjabarkan secara deskriptif tentang Designer Toys dilakukan juga analisa studi korelasi. Yang dimaksud dengan analisa studi korelasi adalah peneliti menunjukan hubungan suatu koefisien variabel objek dengan variabel-variabel objek lain. Hal ini digunakan untuk menguji hipotesis tentang hubungan mainan jenis Designer Toys dan mainan/toys yang sejenis.

\section{PEMBAHASAN}

\section{Ragam Macam Desainer Toys}

Designer Toys adalah jenis toys yang diproduksi secara limited editions (berkisar antara 10 sampai 2000 buah) diciptakan berdasarkan konsep ilustrasi dari artis dan desainer. Materi untuk membuat sebuah Designer Toy sangat beragam, namun bahan vynil dan plastik ABS (Acrylonitrile butadiene styrene). Untuk beberapa kondisi tertentu bahan dari berbagai macam varian seperti kayu, metal dan resin kadang digunakan. Bahan lain berupa boneka isi (plush), kain dan latek merupakan aplikasi lain dalam jenis Designer Toys.

Para pencipta Designer Toys biasanya berlatar belakang sebagai desainer grafis/produk, ilustrator, para seniman low-browii. Animo terhadap toys jenis ini juga menarik minat para seniman klasik, bahkan masyarakat umum dari beragam latar belakang. Perusahaan pencipta mainan khusus jenis ini seperti Toy2R, Kidrobot MediCom Toy bermunculan dan mengalami pertumbuhan yang pesat hingga saat ini. Biasanya pabrik pembuatan vinyl toys terdapat di China, beberapa produk akan melalui proses retouch 
di Jepang. Jarang sekali pembuatan produk vynil toys secara masal dilakukan Amerika karena isu lingkungan.

Jenis Designer Toys terbagi dalam berbagai macam jenis utama menurut material bahan, antara lain :

Urban vinyl, jenis ini berupa action figure yang terbuat dari bahan vynil atau plastik ABS. Istilah ini secara umum sering tertukar dengan sebutan untuk Designer Toys, hal ini dikarenakan rata-rata produk dari Designer Toys adalah jenis Urban Vynil. Jenis seperti inilah yang pertama kali diciptakan oleh Michael Lau. Seperti layaknya Designer Toys, figure dari urban vynil diproduksi secara terbatas dan memiliki konsep desain yang unik. Umumnya konsumen toys jenis ini adalah para kolektor mainan yang serius, sehingga para konsumennya rata-rata memiliki usia yang sudah dewasa.

Selain Michael Lau, salah satu artis jepang Takashi Murakami merupakan tokoh terkenal dibidang urban vynil. Ketenarannya semakin dilihat dunia karena kolaborasi dengan produk fashion terkemuka Louis Vuitton. Contoh bentuk urban vynil yang terkenal adalah karya Jamie Hewlett yang diproduksi oleh perusahaan mainan Kidrobot, dengan membuat figur berdasarkan personil grup band virtual Gorillaz. Saat ini vynil figur karya Takashi Murakami dan Jamir Hewlett yang asli sangat dicari oleh kolektor mainan, harganya bahkan mencapai ribuan dollar US.

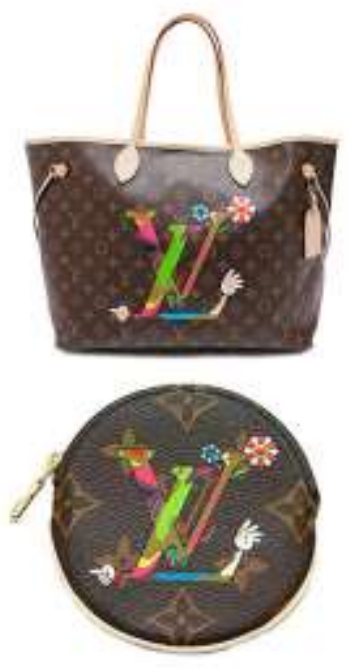

Gambar 1:

Contoh karya kolaborasi

Takashi Murakami dan Louis Vuitton

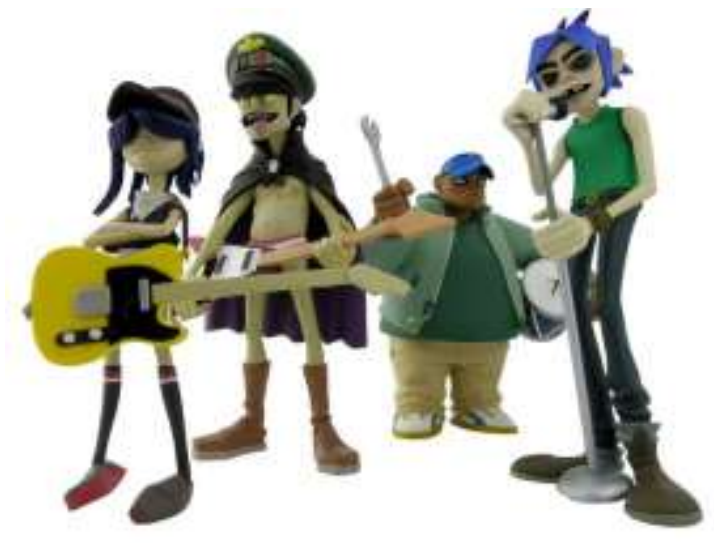

(Sumber: Museum of Contemporary Art) 
Gambar 2:

Contoh karya Jamie Hewlett untuk figur band Gorillaz

(Sumber: Kidrobot Catalogue)

Resin toy, untuk beberapa artis memilih media resin selain plastik vynil. Biasanya teknik yang dilakukan melalui proses pencetakan resin dan dilanjutkan dengan proses pengecatan. Pemilihan bahan resin biasanya disebabkan sedikitnya jumlah Designer Toys yang akan diproduksi. Cara ini lebih banyak mengkonsumsi waktu dan tenaga, tetapi lebih murah dari segi biaya. Tidak seperti umumnya vynil toys, resin toys biasanya dibuat secara manual oleh artis itu sendiri baik proses membentuk, mencetak dan mewarnai.

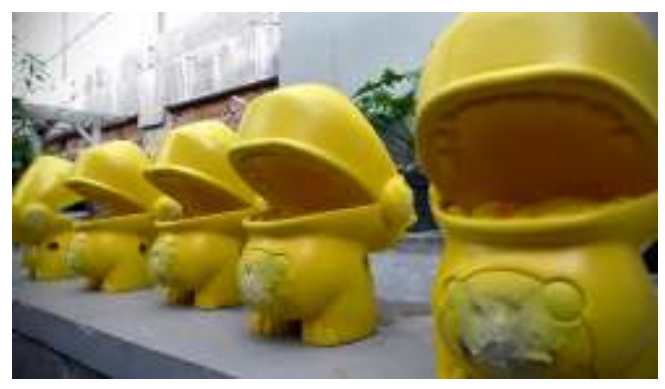

Gambar 3:

Proses pembuatan resin toy Yellow Dino

(Sumber: Foto dari Data Pribadi 2011)

Designer plush, jenis ini adalah jenis varian pada Designer Toys. Plush adalah jenis Designer Toy yang terbuat dari bahan kain tekstil, tidak seperti pada umumnya produk lain yang melalui proses cetak. Proses pembuatan Designer plush lebih mirip dengan proses pembuatan stuffed toy yang mirip dengan pembuatan bantal. Wujud desian yang umum digunakan berbentuk modifikasi hewan dan manusia karikatural, banyak ditemukan juga bentuk unik yang sama sekali tidak berangkat dari bentuk manusia dan hewan. Friends With You (FWY) merupakan produk Designer plush yang diciptakan oleh kolaborasi beberapa seniman terkenal seperti Jeff Koons, Takashi Murakami, dan Damien Hirst.

Jenis lain dari designer plush adalah Uglydools, yang diciptakan oleh David Horvath dan Sun-Min Kim dari perusahaan Pretty Ugly. Produk jenis ini cukup laku di pasaran dan memiliki beragam jenis yang ikonik. 


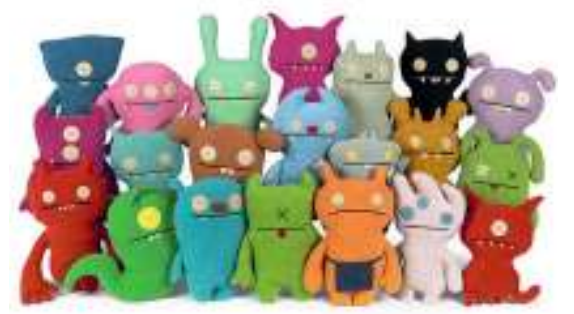

Gambar 4:

Berbagai Jenis Designer Plush dengan merk Uglydools

(Sumber: Uglydools Catalogue)

Selain jenis-jenis Designer Toys seperti yang telah dibahas ada jenis lain yang berbeda bukan hanya ditinjau dari material bahan. Penggabungan fungsi atau kolaborasi Designer Toys dengan berbagai macam alat menciptakan sub kategori tersendiri. Rumah produksi Mimoco menggabungkan flashdisk dengan Designer Toys, hal ini mendapat sambutan baik oleh pasar.

Do It Yourself (DIY) adalah salah satu varian lain Designer Toys yang menawarkan konsep dalam penjualannya. Hampir semua produsen Designer Toys khususnya Urban vinyl menjual produk tanpa desain (blank product). Para produsen mengajak konsumen untuk berkreasi dengan template berupa mainan yang diciptakan. Figur kosong Designer Toys seolah menjadi kanvas yang siap untuk dijadikan media kreasi. Inovasi seperti ini menjadi daya tarik tersendiri bagi konsumen, terbukti dengan banyaknya pameran karya costumize yang bersifat kompetisi atau sebagai media pameran seni saja.
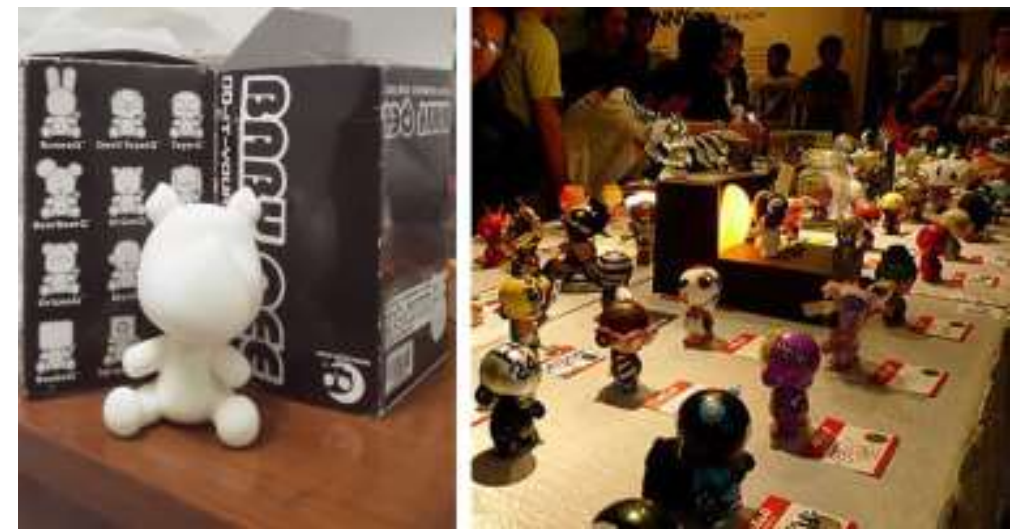

Gambar 4:

Blank Designer Toys Dan Pameran Costumize DIY

(Sumber: Data Pribadi Penulis 2014) 


\section{Kaitan Identitas Urban dengan Desainer Toys}

Terlahir dari kebudayaan urban, Designer Toys tentu menjadi wacana bagi segala kondisi yang berkaitan dengan urban. Identitas seperti ini sudah terlihat jelas sejak Michael Lau menciptakan genre mainan baru ini. Hal yang menjadi ciri kaum urban seperti musik hiphop, tekno atau jenis musik elektronik lainnya menjadi salah satu aspek yang menonjol. Fashion yang khas adalah faktor utama untuk mengidentifikasi nuansa urban. Gaya hidup, komunitas, profesi dan lain sebagainya dijadikan bahan untuk menciptakan karya Designer Toys.

Designer Toys telah menjadi identitas sekaligus anekdot dari kondisi urban itu sendiri. Berkesan naif dan lugu namun bentuk visual yang ditawarkan tepat mengenai sasaran. Beberapa kritikus seni menamai jenis seni seperti ini sebagai karya lowbrow atau sering disebut juga kitsh. Mereka tidak bisa menentukan klasifikasi yang pantas untuk seni jenis ini, bahkan berpendapat bahwa karya tersebut tidak bisa disebut sebagai karya seni.

Sebuah istilah "lowbrow" yang berlawanan dengan "highbrow" yang berarti kaum intelektual di bidang seni dan kebudayaan. Robert Williams menyatakan dirinya adalah seniman lowbrow pertama (1979), berdasarkan judul buku kumpulan karya lukis dia sendiri "Lowbrow Art of Robert Williams". Buku ini berisi karya Robert Williams dalam bentuk lukisan surealis, komik, poster, desain iklan atau ilustrasi otomotif. Pada tahun 1994, Robert Williams dan rekan-rekan yang memiliki kesamaan pandangan tentang Lowbrow, menerbitkan majalah berjudul Juxtapoz Art \& Culture Magazine yang nantinya menjadi cikal bakal media massa pertama untuk aliran seni dan desain Lowbrow.

Kaitan antara lowbrow, kitsh dan Designer Toys memiliki peranan penting yang saling bertautan. Bentuk seni yang naif justru membuka pandangan baru tentang diskusi seni. Persamaan mereka terletak dari konsep yang "langsung tembak" untuk menjadi ide dasar berkarya. Contoh bisa dilihat dari karya Designer Toys dari rumah produksi ThreeA yang diprakarsi oleh Ashley Wood. Segala aspek yang sedang populer saat ini akan ditampilkan, digabungkan, dipelintir dan dicampur aduk sehingga tercipta bentuk gabungan yang menarik. Tidak perlu konsep yang mendalam, yang penting gaya yang nikmat untuk dipandang. Konsep cerita akan mengikuti dari ilustrasi yang dibuat dari 
sketsa-sketsa gambar. Maka sering sekali identitas populer bermunculan dari visual Designer Toys terjadi begitu saja, saling tumpuk menumpuk.

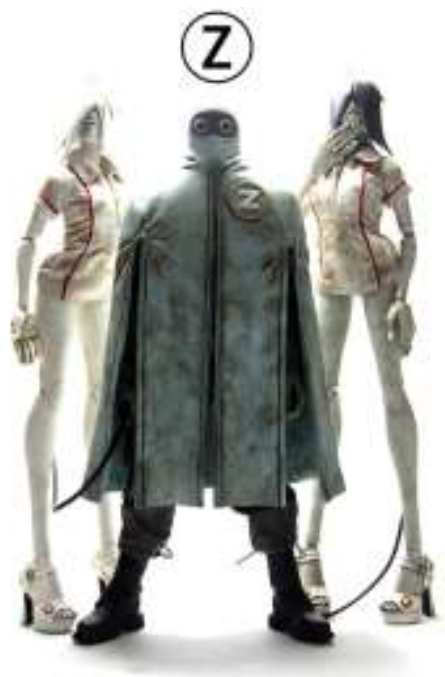

\author{
Gambar 5: \\ Zombot Dari ThreeA @ \\ (Sumber: ThreeA Toys)
}

Dari contoh gambar produk Designer Toys diatas, digambarkan seorang tokoh dengan jas yang mirip dengan jas laboratorium dengan modifikasi bentuk seperti jubah/cape jaman pertengahan di Eropa namun mengenakan google dengan bentuk teknologi tinggi dan memiliki tangan robot. Inisial Z melambangkan Zom, Zombie atau nama tokoh itu sendiri Zombot. Tokoh ini digambarkan memiliki dua pendamping di kanan dan kiri berupa sepasang zombie wanita seksi yang berkulit albino. Walaupun berkulit albino, salah satu dari Zombie tersebut memiliki rambut hitam dan memiliki postur tubuh model yang lengkap dengan kostum suster yang sangat seksi dan sepatu high heels.

\title{
IV. PENUTUP
}

Designer Toys merupakan jenis baru dalam dunia mainan modern, terhitung dari tahun 1999. Walaupun demikian kontribusi mainan jenis ini dalam wacana desain dan seni begitu penting dilihat dari perkembangannya yang sedemikian besar hingga kini. Sesuai dengan sejarahnya, Designer Toys sangat erat kaitannya dengan kebudayaan perkotaan yang identik dengan kemajuan teknologi, dromologi dalam budaya dan tingkat kompleks tatanan masyarakat. Konsep yang berasal dari hal praktis dan populer sering dianggap sebagai produk desain semata yang lebih mengutamakan selera pasar. Akan tetapi setelah dikaji lebih mendalam terkandung nilai-nilai filosofis seni dalam perkembangan Designer Toys.

Menurut Matthew Kieraniii, penciptaan karya seni harus mampu merangsang daya imajinasi orang. Sedangkan karya seni yang hebat harus mampu memberi inspirasi bagi 
segala macam golongan masyarakat dan bertahan dalam laju jaman. Dilihat dari pernyataan tentang karya seni yang hebat, Designer Toys memang harus membuktikannya pada masa mendatang. Ditilik dari perubahan jaman yang kian laju seperti saat ini, belum tentu jenis mainan baru ini mampu bertahan.

Dalam perkembangan seni sering terjadi perbedaan yang saling berlawanan dengan ilmu desain. Seni dan desain yang saling tuding dan menjatuhkan. Seperti halnya kaum intelektual seni yang merasa seni harus memiliki bentuk yang eksklusif dan "aneh", begitu pula para pelaku seni terapan/desainer yang menganggap metoda inovasi yang dimilikinya adalah teknik terbaik. Designer Toys sering dianggap remeh oleh pihak yang tidak mengenal perkembangan mainan modern.

Pada dasarnya setiap perkembangan visual pada jaman post-modern, bentuk dan perupaan tidak bisa hanya dinilai dari perspektif tunggal. Namun butuh pemahaman secara menyeluruh dan terbuka pada temuan baru. Hal itu telah dibuktikan dari lahirnya gerakan Pop-Art di Eropa dan Amerika sekitar tahun 1950. Gerakan seni ini berhasil mengganti paradigma konservatif tentang seni.

Designer Toys walaupun sering dijadikan bahan diskusi dan wacana khususnya pada kehidupan urban, namun kerap teralienasi dalam khazanah desain dan seni rupa. Tampil seperti pendatang baru, sama halnya seperti wacana game digital, Designer Toys lambat laun akan menjadi topik bahasan tersendiri dalam ranah desain dan seni rupa. Sama seperti Ashley Wood dalam menciptakan karakter yang seolah potongan kolase dari ikon populer, seni tidak bisa diukur oleh logika seperti halnya fisika atau matematika. Seperti yang dikatakan Goenawan Mohammad, terkadang seni hadir seperti musik jazz yang improvisasi. Ringan terbawa arus, tanpa kaidah tertentu, penuh kejutan kecil tak terencana namun berhargaiv . 


\section{DAFTAR PUSTAKA}

Setijowati, Adi dan Kawan-Kawan (Ed). 2010. Sastra dan Budaya Urban dalam Kajian Lintas Media. Surabaya: Airlangga University Press, 10.

Hundertmark, Christian. (2010). The Art of Rebellion 3:The Book About Street Art, Gingko Press, USA.

Perloff, Majorie. (1989). Postmodern Genres, Norman: University of Oklahoma Press, Oklahoma, USA.

Eldridge, Richard. (2001). An Introduction to the Philosophy of Art. Cambridge: Cambridge University Press,214-222.

Williams, Robert. (1979). The Lowbrow Art of Robert Williams, Rip Off Press, Inc, USA.

Osterworld,Tilman. (2003). Pop Art. Germany: Taschen, Cologne.

Williams, Robert; Lavella, Mike. (2006). The Hot Rod World of Robert Williams, Motorbooks Intl, Menasha, Wisconsin

Wong, Amos, (2007), November. "Design Style". Newtype USA 6 (11) 142-143.

\section{REFERENSI LAIN}

'Servin, A., Bohlin, G., \& Berlin, L. (1999). Sex differences in 1-, 3-, and 5-year olds' toy-choice in a structured play-session. Scandinavian Journal of Psychology, 40, 43-48.

ii Williams, Robert, (2006, February). " lowbrow art" Juxtapoz Art \& Culture Magazine\#61

iii Kieran, Matthew. (1996) Journal of Aesthetics and Art Criticism 54 (4):337-351.

iv Mohammad, Goenawan, (2013, agustus). "Catatan Pinggir" Tempo, 122 